\title{
LA LITERATURA INFANTIL Y SU IMPORTANCIA EN EL APRENDIZAJE DE NIÑOS Y NIÑAS: DE LA TEORÍA A LA PRÁCTICA
}

\author{
Jaime Caiceo Escudero \\ Universidad de Santiago de Chile \\ jcaiceo@ hotmail.com \\ Estela Socías Muñoz \\ Universidad Mayor, Chile \\ estelafrancisca.socias@gmail.com
}

\begin{abstract}
RESUMEN
El propósito de esta investigación teórico-práctica es destacar la importancia de la literatura infantil para motivar e involucrar a los niños con la lectura a fin de despertar la creatividad y el desarrollo de la imaginación. Para ello, se plantean tres aspectos fundamentales: (i) Funciones de la literatura infantil; (ii) Papel del docente como promotor de la literatura infantil; y (iii) Estrategias que favorecen el aprendizaje natural de la lectura, relacionadas con la literatura para niños. El análisis se fundamenta en el enfoque constructivista del aprendizaje del lenguaje. Se concluye con la mención de algunas consideraciones prácticas para mejorar el trabajo de la literatura infantil en el aula.
\end{abstract}

Palabras clave: Enseñanza infantil, métodos de enseñanza, motivación lectora.

\section{A LITERATURA INFANTIL E SUA IMPORTÂNCIA NA APRENDIZAGEM DE CRINAÇAS: DA TEORIA A PRÁTICA}

\section{RESUMO}

O propósito desta investigação teórico-prática é destacar a importância da literatura infantil para motivar e envolver as crianças com a leitura a fim de despertar a criatividade e o desenvolvimento da imaginação. Para ela, planejam-se três aspectos fundamentais: (i) Funções da literatura infantil; (ii) Papel do docente como promotor da literatura infantil, e (iii) Estratégias que favoreçam a aprendizagem natural da leitura, relacionada com a literatura para crianças. A análise fundamenta-se no enfoque construtivista da aprendizagem da linguagem. Conclui-se com a menção de algumas considerações práticas para melhorar o trabalho da literatura infantil na aula.

Palavras-chave: Ensino infantil, métodos de ensino, motivação leitora.

\section{CHILDREN'S LITERATURE AND ITS IMPORTANCE IN THE LEARNING OF BOYS AND GIRLS: FROM THEORY TO PRACTICE}

ABSTRACT 
The purpose of this theoretical-practical research is to highlight the importance of children's literature to motivate and engage children with reading in order to awaken creativity and the development of imagination. For this, three fundamental aspects are proposed: (i) Functions of children's literature; (ii) The teacher's role as a promoter of children's literature; and (iii) Strategies that favor the natural learning of reading, related to children's literature. The analysis is based on the constructivist approach of the language learning. It concludes with the mention of some practical considerations to improve the work of children's literature in the classroom.

Keywords: Children's teaching, teaching methods, reading motivation.

\section{LA LITTÉRATURE DES ENFANTS ET SON IMPORTANCE DANS L'APPRENTISSAGE DES GARÇONS ET DES FILLES: DE LA THÉORIE À LA PRATIQUE}

\section{RÉSUMÉ}

L'objectif de cette recherche théorico-pratique est de souligner l'importance de la littérature de la petite enfance pour motiver et impliquer les enfants dans la lecture afin d'éveiller la créativité et le développement de l'imagination. Pour cela, trois aspects fondamentaux sont proposés: (i) Les fonctions de la littérature pour enfants; (ii) Le rôle de l'enseignant en tant que promoteur de la littérature pour enfants; et (iii) Des stratégies qui favorisent l'apprentissage naturel de la lecture, en relation avec la littérature pour enfants. L'analyse est basée sur l'approche constructiviste de l'apprentissage des langues. Il se termine par la mention de quelques considérations pratiques pour améliorer le travail de la littérature pour enfants en classe.

Mots-clés: éducation de la petite enfance, méthodes d'enseignement, motivation à la lecture.

\section{INTRODUCCIÓN}

La literatura infantil constituye un medio poderoso para la transmisión de la cultura y la integración de las áreas del saber. Además, contribuye en lo más importante de la educación que es la formación de los valores, cumpliendo un papel importante y esencial tanto en el hogar como en la escuela, favoreciendo de esta forma un acercamiento a la lectura y la escritura. Es de antigua data este tipo de literatura escrita; en efecto, en la baja Edad Media ya hubo expresiones literarias de este tipo, pero el infante era visto como un adulto pequeño en sus escritos sobre tablitas de madera. Gracias a la imprenta en los inicios de la época moderna, el primer gran pedagogo, Juan Amos Comenius (1592-1670) escribió el primer libro ilustrado para niños con juegos infantiles, escenas históricas y cuadros religiosos. Posteriormente, el francés Charles Perrault (1628-1703), escribió cuentos clásicos, muy bien ilustrados, tales como: La Cenicienta, El Gato con Botas, La Bella Durmiente, Cuentos del Pasado y Cuentos de Mamá Oca. En el siglo XIX sobresale el danés Hans Christian Andersen (1805- 
1875) con innumerables publicaciones para niños; algunos de ellos son: EI soldadito de plomo, El molino de viento, El farol viejo, El ruiseñor, El sapo, El patito feo, El abeto o El último sueño de la vieja encina y El sastrecillo valiente (MORENO, 1998). En el siglo pasado, en Chile se destaca Marcela $\mathrm{Paz}^{1}$, quien posee un sinnúmero de textos infantiles, pero se destaca su colección sobre un personaje infantil: Papelucho, Papelucho casi huérfano, Papelucho historiador, Papelucho detective, Papelucho en la clínica, Papelucho perdido, Papelucho, mi hermana Ji, Papelucho misionero, Diario secreto de Papelucho y el marciano, Papelucho, mi hermano Hippie, Papelucho en vacaciones (MEMORIA CHILENA, 2020). Como puede apreciarse, la literatura ha estado presente por siglos no solo para entretener a los niños y niñas sino que especialmente para promoverlos a la lectura y a internalizarles los valores ya que muchos cuentos terminaban en una conclusión axiológica.

Los objetivos de este artículo son tres: Desarrollar las principales funciones de la literatura infantil; describir el rol del docente como promotor de la literatura infantil; y (iii) presentar algunas estrategias que favorezcan el aprendizaje natural de la lectura, relacionadas con la literatura para niños, niñas y jóvenes. Esto es lo que se desarrollará en los puntos siguientes, tanto en lo teórico como en la aplicación práctica.

\section{MARCO TEÓRICO}

La literatura es la forma más adecuada para que los seres humanos se comuniquen entre sí; es algo propio del ser del hombre, puesto que es algo connatural a su esencia, la racionalidad, la cual le permite la comunicación a través de la expresión oral o escrita, especialmente esta última en el mundo de hoy, en que existe poca comunicación dialógica, como plantea el filósofo Martín Buber (2017). A través de sus escritos, la persona puede

[...] transmitir sus pensamientos, sus ideas, sus necesidades, su fantasía. Esto último nos remite inmediatamente a la literatura infantil, pues uno de los componentes de la misma es, justamente, la fantasía. El niño vibra con mundos imaginarios de cuentos de hadas y duendes; en donde existen muñecos de trapo que se comportan como humanos; en donde aparecen animales que hablan; sin embargo, siempre existen en esos cuentos enseñanzas para los niños, hay transmisión de valores. Como puede apreciarse, algo tan sencillo como un cuento para niños nos lleva, a lo menos, a considerar tres disciplinas filosóficas: La antropología (la literatura infantil es una realidad propiamente humana), la ontología (la racionalidad, propia del

\footnotetext{
${ }^{1}$ Cuyo verdadero nombre era Ester Huneeus Salas (1902-1985).
} 
ser del hombre, permite pensar y transmitir ese pensamiento) y la axiología (los cuentos son un medio de transmisión de valores). (CAICEO, 2006, p. 46).

Por otra parte, los niños aprenden a partir del lenguaje que escuchan; de ahí que, cuanto más rico sea el entorno lingüístico, más rico será el desarrollo del lenguaje. El proceso de apropiación del lenguaje continúa a lo largo de los años escolares, así que esos años deben estar llenos de las imágenes y el vocabulario excitante que ofrece la literatura para niños. El término literatura podría definirse desde una perspectiva histórica o cultural, desde la óptica de un crítico u otro, o desde uno u otro lector. Como promotores de lectura entendemos la literatura como la construcción imaginaria de la vida y el pensamiento en formas y estructuras de lenguaje, integrados en un conjunto de símbolos que provocan una experiencia estética.

El fundamento de este género es la función imaginativa de la literatura que permite al alumno el enriquecimiento personal, el conocimiento del acervo cultural de su contexto social, la reafirmación de su identidad y el contacto con diferentes mundos lo cual favorece el desarrollo del pensamiento divergente. Así, la literatura para niños, en su mayoría escrita por adultos, es aquella que pudiendo tener o no al niño como protagonista, refleja sus emociones y experiencias; es aquella que teniendo la óptica del niño como centro les ofrece, no siempre, finales felices (SOCÍAS, 2006).

Se puede afirmar que el niño, desde muy pequeño, participa de la literatura como juego, diversión o entretenimiento. Cuando va a la escuela también tiene contacto con la literatura no sólo con fines lúdicos sino con otras intenciones: aprender a leer y escribir, culturales, morales, religiosas y pedagógicas. En este sentido, es oportuno que se contacte con los libros adecuados. La relación con libros para niños se puede presentar desde antes de nacer o desde la cuna, cuando se coloca en las manos del niño su primer libro o cuando escucha las rimas que por generaciones cantaron madres y abuelas. Cómo olvidar: Arroz con leche, Los pollitos, La muñeca vestida de azul, Duérmete mi niño, Mambrú. Estos eventos llenos de melodía, vocabulario e imágenes van constituyendo el lenguaje que le permite al niño entender el mundo y el lugar que él ocupa. Lo más importante y que es relevante de la literatura infantil es motivar e involucrar a los niños con la lectura a fin de despertar la creatividad y el desarrollo de la literatura infantil en el aula. Los niños aprenden a partir del lenguaje que escuchan; de ahí que, cuanto más rico sea el entorno lingüístico, más rico será el desarrollo del lenguaje. El proceso de apropiación del lenguaje continúa a lo largo de los años escolares, así que esos años deben estar llenos de las imágenes y el vocabulario excitante que ofrece la literatura para niños. El término literatura podría definirse desde una perspectiva histórica o cultural, desde la óptica de 
un crítico u otro, o desde uno u otro. Esta experiencia puede ser la reconstrucción viva o la expansión de eventos anteriores, o la creación de nuevas experiencias a partir de la interacción con géneros diferentes. En este sentido "un género es una clase o tipo de literatura que tiene un conjunto de características comunes" (LUKENS, 1999, p. 13).

De manera que podemos hablar de cinco géneros: (i) ficción o literatura novelesca o de misterio; (ii) literatura tradicional, representado por las fábulas, leyendas y mitos; (iii) fantasía, relacionado con temas fantásticos; (iv) poesía; y (v) realista, vinculado con las biografías. Para ello, se plantean tres aspectos fundamentales: a) Funciones de la literatura infantil; b) Papel del docente como promotor de la literatura infantil; y c) Estrategias que favorecen el aprendizaje natural de la lectura, relacionadas con la literatura para niños. El análisis se fundamenta en el enfoque constructivista del aprendizaje del lenguaje. Por este motivo es relevante expresar que la literatura desarrolla la imaginación y curiosidad de los niños ayudándoles a apreciar la naturaleza, la gente y las experiencias a través de formas no consideradas por ellos. Ante la invasión explícita que ofrece la televisión, la literatura ofrece nuevas dimensiones a la imaginación del niño que solo se le haría difícil descubrir. Los libros para niños tienen el poder para crear imágenes en las mentes del lector y ampliar su imaginación (SOCÍAS, 2006).

Es relevante agregar que leer es un arte y como todo arte se aprende viviéndolo, experimentando el arte de leer, el learning by doing de Dewey (CAICEO, 2016). Si consideramos la lectura como una de las mejores artes, podríamos ver el resultado en cursos superiores, en lo que leen. Por eso es que si se maneja bien el arte de leer, podrá el individuo estudiar sobre este. La literatura no puede reducirse al contenido o al argumento. La forma y el fondo son inseparables, dado que la literatura es experiencia transmitida a través del lenguaje artístico, siendo este, el lenguaje más humano de todos. La literatura no se aprende, se vive y esa vivencia le permitirá al lector transformarse no solo en su proceso como lector, sino en su formación como ser humano. Este análisis se verá cuando se aborden las estrategias utilizadas para el conocimiento del libro y la lectura.

En el contexto anterior, se entiende lo expresado por diversos autores (ALLIENDE, CONDEMARÍN, 1997; QUINTERO, 1992; VANNINI, 1995), quienes, a su vez, describen las funciones de la literatura infantil y juvenil: (i) Amplía el horizonte intelectual y artístico de los niños y adolescentes, así como su universo social, afectivo, imaginativo y lingüístico. (ii) Divierte y activa la curiosidad. (iii) Estimula el desarrollo del pensamiento libre y creativo. (iv) Proporciona temas, motivos y detalles para nutrir su inspiración. (v) Ayuda a comprender el mundo en el que el lector vive y lo ayuda a enfrentarlo. 
En la práctica educativa diaria se ha podido detectar que se sigue aplicando una metodología tradicional (memorística, reproductiva, poco participativa y creativa, irreflexiva y acrítica), y el texto literario, generalmente el cuento, es utilizado como un tranquilizante para el comportamiento de los niños. De ahí que, consideramos necesario enfatizar que la literatura es un recurso clave para lograr el sano desarrollo del pensamiento creativo, y así favorecer su expresión espontánea ante cualquier actividad del aprendizaje escolar. La lectura y producción de textos literarios como cuentos, poemas o canciones desarrollan las capacidades creativas de los niños. Además, la biblioteca de los establecimientos educacionales, son el centro importante de las conductas de los educandos, ya que para uno de los autores de esta comunicación, ellas son la casa de los libros, el lugar donde pueden desarrollar todas las actividades en cuanto al fomento lector, bibliotecas abiertas al alcance de los niños, por supuesto que con un mediador entre el libro y el niño. La literatura tiene el primer y gran valor educativo cuando el niño o niña comienza a introducirse en el aprendizaje de la lectura y escritura.

A pesar de que las puertas de muchas aulas continúan cerradas a la verdadera experiencia literaria, se percibe cómo los grandes lectores y escritores coinciden en señalar el camino para la formación de estos: leer primero de "viva voz", es una vivencia compartida, de una manera joven y vital, para ir sembrando poco a poco, en los futuros lectores, el deseo de leer por su propia cuenta.

La relación literatura-escritura ha sido comprobada en diversas investigaciones, llegándose a afirmar que la interacción permanente del niño con la lengua escrita en el hogar y la escuela favorece la producción de textos, pues, la lectura frecuente ayuda no sólo a escribir correctamente, sino también, creativamente. La producción escrita de los niños que provienen de ambientes con abundante literatura, refleja mayor sofisticación en cuanto a manejo del vocabulario y la sintaxis; asimismo, presentan palabras, frases y patrones que pudieran haber sido tomadas de manera consciente o inconsciente de los libros leídos. De ahí que, "el desarrollo de la composición en la escritura no reside en escribir solo, requiere leer y ser leído. Sólo a partir del lenguaje escrito de otros pueden los niños observar y comprender convenciones e ideas en conjunto" (SMITH, 1982, p. 75).

Asimismo, el cuento constituye una herramienta que estimula el pensamiento creativo, imaginativo y crítico de los niños, permitiéndoles expresarse en diversas formas. Desde el nivel parvulario y de educación inicial, los niños demuestran interés por explorar y establecer contacto con diferentes materiales de lectura y escritura, los cuales inducen a manifestar vivencias y experiencias reales e imaginativas, dando lugar a la expresión de ideas, emociones 
y sentimientos propios que permiten aflorar su mundo interior. Por ello, el uso del cuento se convierte en instrumento de enseñanza útil para acompañar emocional y creativamente a los niños en su proceso de formación.

La literatura infantil constituye un medio poderoso para la transmisión de la cultura, la integración de las áreas del saber. Además, contribuye en lo más importante de la educación que es la formación de los valores, cumpliendo un papel importante y esencial, tanto el hogar como la escuela, favoreciendo de esta forma un acercamiento a la lectura y la escritura. Los docentes al igual que los bibliotecarios deben participar en este proceso educativo porque son los indicados de poder acercar mediante técnicas el amor a los libros; todos están conscientes que un profesor que tiene un rincón de libros donde cada niño podrá elegir el libro que más le llame la atención y no imponer solo los indicados en el programa, los anima y mantiene activas sus mentes, y si, además, los hacer partícipes de los relatos, mediante cuenta cuentos y realizando juegos con títeres, disfraces, etc., la situación es mucho más motivadora; de esta manera, cada niño encontrará el sentido a escuchar, leer y escribir, según sea su edad.

Un aula donde los alumnos estén involucrados con literatura debe tener una biblioteca con espacio suficiente para que los niños disfruten de sus libros preferidos. La procedencia de estos materiales puede ser el de la biblioteca de la escuela, pero siempre debe haber en los estantes los libros favoritos y otros títulos nuevos e interesantes. La selección de los materiales debe ser cuidadosa, acorde a la edad e intereses de los alumnos, y disponible en varios ejemplares para que pequeños grupos lean y luego conversen acerca de lo leído. De ahí que deban existir libros que tengan una atracción inmediata, que amplíen la imaginación y las habilidades, historias con cierta profundidad que reten a leerlas varias veces y reflexionar, variedad de géneros; materiales vinculados con los libros que captan la atención inmediata de los alumnos son aquellos de fácil acceso y con una exhibición atractiva. Los alumnos se inclinan a decir más cosas acerca de lo que leen cuando pueden sostener el libro en sus manos. Disponer en el aula de clase de materiales de lectura variados (i.e. periódicos, cuentos, enciclopedias, manuales, revistas, catálogos, poemarios, etc.) favorece que los niños vayan apropiándose de los usos del lenguaje, de sus funciones y características (SOCÍAS, 2006).

El docente, al leer en voz alta, produce entretenimiento de los alumnos, historias que pudieran no estar en capacidad de leer solos. Esta actividad de reconocida importancia provoca gran impacto en los recuerdos de los niños, por cuanto al leer el docente se convierte en un modelo de lectura mostrando lo que un lector hace y ofreciendo oportunidades para desear leer. 
Esta estrategia permite a los niños tener temas para conversar, y así ampliar sus habilidades expresivas; a esto se llama cuenta cuentos.

Por otra parte, existe el género poético. Así como en las canciones, los poemas están para ser escuchados. Los niños que escuchan poemas, repitiendo o añadiendo efectos sonoros al mismo, se motivan a querer leer la versión impresa; la razón para tal deseo radica en la familiaridad que adquieren acerca del lenguaje (i.e. melodía, rima). La lectura de poesía debe ser una actividad diaria en el aula; para ello es importante: (i) seleccionar poemas cortos que además de ser leídos por el docente, se transcriben en láminas y se colocan en lugares donde los niños puedan leerlos fácilmente, (ii) incorporar a los niños en la selección de los poemas y que puedan repetir sus poemas favoritos, (iii) conjuntamente con los niños, buscar música que acompañe la lectura de los poemas, (iv) invitar a los niños a representar (i.e. dramatizaciones, dibujos, plastilina) los poemas escuchados.

Los infantes se forman como lectores literarios a través de la lectura de libros infantiles. Saber cómo son estos textos, qué temas abordan, qué características presentan. La tarea como mediadores de literatura para niños en la escuela nos lleva a identificar, analizar, comprender y explicar los múltiples factores que intervienen para que la literatura llegue a los lectores, tales como: medio familiar y escolar, práctica pedagógica, formación docente, contacto con los textos, experiencia personal de lectura, o contexto cultural. De esta manera se aspira a lograr una comprensión más profunda del problema y ofrecer razones para instalar un espacio que permita otras maneras de relacionarse con la literatura.

Es necesario comprender que desde el momento en que el niño entra en contacto con los libros y empieza a leer hasta el tiempo en que va dominando la lectura y encuentra en ella un placer, hay un largo proceso que la escuela debe alimentar y guiar, y que el rol de la escuela de hoy es promover un cambio: de no lectores a lectores eficientes a través de la literatura para niños. Se persigue estimular el poder creativo y desarrollar la imaginación. Ello se logra con docentes que orienten y proporcionen estímulos, que ofrezcan un clima para la lectura y producción de textos literarios, que motiven, involucren al niño con la lectura y conversación sobre textos literarios; todo, a fin de despertar y canalizar su actitud crítica. Siempre teniendo presente que los alumnos se transforman en lectores críticos a medida que van utilizando sus conocimientos anteriores y sus experiencias previas para conocer, predecir, clasificar, analizar, evaluar, comparar, opinar e interpretar. Mediante el manejo de situaciones lúdicas el niño logrará la confianza en lo que es capaz de inventar mediante el uso cada vez más preciso de la lengua. 
Este marco teórico ha estado entrelazado con teorías y sugerencias de aplicación de la literatura infantil y de la lecto-escritura en la escuela, a fin de despertar en los niños, niñas y jóvenes el interés por los libros y su contenido, el cual le presenta el mundo, su historia y la ciencia en todo su esplendor.

\section{DESARROLLO METODOLÓGICO}

En esta comunicación, fruto de una investigación, se está frente a un paradigma cualitativo, el cual se ha ido constituyendo como propio de las ciencias sociales, entre las cuales se encuentran las humanidades y dentro de ellas, la literatura. El paradigma es definido como un "conjunto de logros compartidos por una comunidad científica, empleados por esta para definir problemas y buscar soluciones legítimas" (HURTADO, 2010, p. 29). El paradigma, a su vez, "implica una manera de entender y valorar [...] (la realidad), establece cuál problema debe resolverse, la manera de formularlo, las técnicas a utilizar y cómo el resultado obtenido debe ser interpretado e inserto en el conjunto de conocimientos que conforman el paradigma" (HURTADO, 2010, p. 29).

Por otra parte, se está frente a una episteme fenomenológica y hermenéutica. Las denominadas ciencias del espíritu buscan la comprensión de los fenómenos humanos con sus respectivos significados culturales (CAICEO, 2018). Para Edmund Husserl, principal exponente de la fenomenología, este es un estudio de los fenómenos tal como son experimentados, vividos y percibidos por el hombre (HUSSERL, 1962). La hermenéutica que, originalmente para Dilthey era una interpretación de los fenómenos, para Hans-Georg Gadamer (1993) va a ser la comprensión de los mismos. El sentido real que este último filósofo alemán le otorga a este concepto “[...] tiene un carácter objetivo, no consiste en entender al otro, sino que entenderse con el otro sobre un texto. Un texto puede ser un acontecimiento histórico, una obra de arte, una obra literaria, etc., pero en cualquiera de esos casos, la comprensión que se logra es histórica, en cuanto ese acontecimiento u objeto está mediado históricamente" (CAICEO, 2018, p. 405). En consecuencia, la investigación es de carácter histórico, descriptivo, analítico, interpretativo y crítico, utilizando el método analítico-documental y la investigaciónacción ${ }^{2}$ : histórica porque se analizará una experiencia en un período de tiempo (2004-2019), descriptiva para especificar los hechos, analítica para distinguirlos, interpretativa para

\footnotetext{
${ }^{2}$ Esto último considerando que especialmente la praxis de este trabajo se propone a partir de la acción misma de los investigadores.
} 
explicarlos y crítica para no aceptar una posición sin el análisis crítico que corresponda (HURTADO, 2010); para realizar la investigación se recurrió al análisis de los documentos y material utilizado en la aplicación en las escuelas para motivar a los niños, niñas y jóvenes a la lecto-escritura durante el período estudiado. A su vez, la metodología que se propone para la enseñanza de la literatura infantil es el constructivismo. Esta teoría

[...] se está transformando en el paradigma pedagógico de nuestro sistema escolar. Poco a poco deja de ser una sugerencia para pasar a transformarse en el modelo educativo que predominará en las aulas, llevando a los docentes a centrarse en el aprendizaje significativo y en la construcción del propio aprendizaje por parte del niño. (CAICEO, 2012, p. 222).

\section{ANÁLISIS ${ }^{3}$ DE LA PRAXIS}

Para comprender la práctica que se detallará es necesario entender que ello se hizo con una formalidad institucional. En efecto, un grupo de escritores ligados a la literatura infantil y juvenil en Chile, convocados por Estela Socías, conformó una Academia con personalidad jurídica sin fines de lucro. Fue así como

[...] el 18 de junio de 2004, se fundó la Academia Chilena de Literatura Infantil-Juvenil -ACHLI-, en la comuna de Providencia. En el acto constitutivo hubo 14 personas, quienes pasaron a ser los socios fundadores, eligiendo a la primera Directiva, siendo nombrada como presidenta, Estela Socías Muñoz, cargo que mantiene hasta el momento actual. Se obtuvo personalidad jurídica como Organización Comunitaria de la Ilustre Municipalidad de Providencia, conforme a la Ley $\mathrm{N}^{\circ} 19.418$, por Decreto Municipal $\mathrm{N}^{\circ} 57$ del 3 de agosto de 2004. (CAICEO, 2019, p. 2-3).

En estos 16 años de existencia de ACHLI sus miembros han participado en charlas en diversas instituciones universitarias y escolares; ponencias en congresos nacionales e internacionales; cuenta cuentos y talleres literarios, tanto en escuelas públicas -especialmente municipales- como en particulares financiadas por el estado; los establecimientos a los cuales se asiste con actividades son de sectores de menores recursos. A su vez, la Academia ha elaborado libros de literatura infantil con énfasis en hábitos y valores que ayuden a la formación integral de las futuras generaciones; ha colaborado en la formación de clubes de narradores, especialmente en escuelas y colegios; algunos de sus miembros han participado en actividades

\footnotetext{
${ }^{3}$ En el sentido de observación y descomposición de las acciones realizadas.
} 
literarias en bibliotecas de diversos establecimientos educacionales, como los Colegios Santa Familia y Santa Isabel de Hungría. Se han organizado concursos literarios, destacándose el concurso $\mathrm{SECHITO}^{4}$, personaje creado al interior de la Academia; mantención constante de colaboración con la Sociedad de Escritores de Chile.

Sin embargo, hay dos hechos académicos relevantes que se desean destacar especialmente: (i) Concurso ganado ante el Consejo Nacional de la Cultura y las Artes en el 2006 que, gracias a los aportes recibidos, se realizó un Congreso de Literatura Infantil en conjunto con la Universidad Mayor, titulado "Leer desde la Cuna". Producto de ello, se publicó un libro Leer desde la Cuna: Un gran desafío, cuyo editor fue el Vice-Presidente de ACHLI, Dr. Jaime Caiceo Escudero, en diciembre del mismo año, inscrito con los derechos de autor con el $N^{\circ}$ 159.705. (ii) Concurso ganado ante la Municipalidad de Providencia en el 2016, gracias al cual se elaboró un Programa de Cuidado del Medio Ambiente para la Televisión, con énfasis en la formación de la niñez y la juventud en el cuidado de su entorno natural.

FIGURA 1 - Texto Leer desde la cuna.

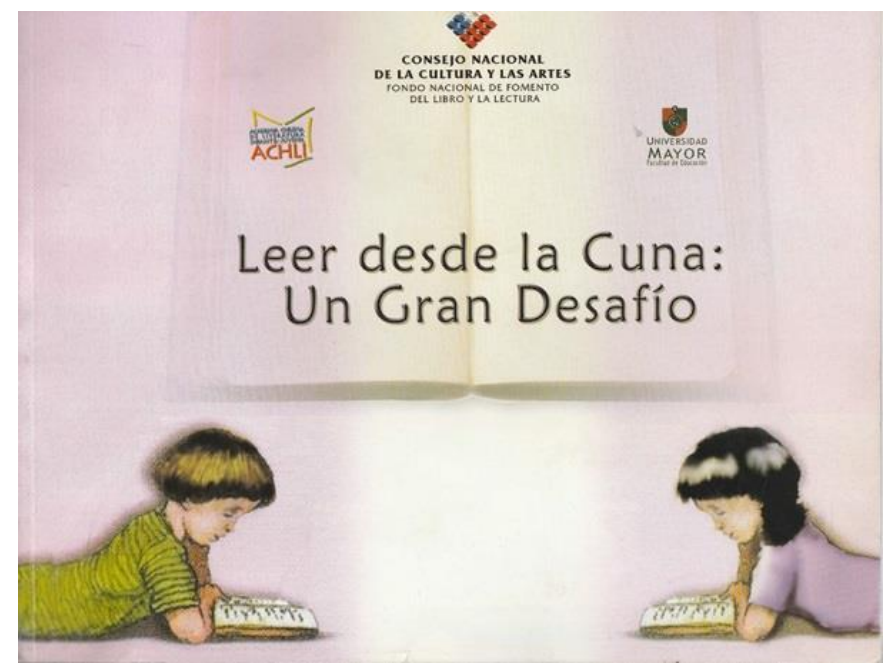

Fuente: Foto archivo personal autores.

A continuación se presentan algunas de las prácticas realizadas por Estela Socías en establecimientos educacionales gratuitos dirigidos por Jaime Caiceo.

\section{RECREOS CULTURALES, REALIZADOS EN COLEGIOS SANTA FAMILIA Y SANTA ISABEL DE HUNGRÍA}

\footnotetext{
${ }^{4}$ Creado por Estela Socías en honor a la Sociedad de Escritores de Chile -SECH-, de la cual era Directora.
} 
Para incentivar la convivencia estudiantil, el acercamiento al libro y la lectura, se crea un espacio de diálogo y de reflexión mediante el juego, la creación de textos, la pintura, el canto, el teatro, la fotografía y el cine. El lema para efectuar estos talleres queda inserto en el proyecto, cuya síntesis se presenta a continuación, el cual fue aceptado y realizado en ambos colegios, gracias al apoyo del director y de las congregaciones respectivas:

Los alumnos son el futuro del país, por lo cual es necesario incentivarlos en las diferentes áreas. La creatividad será el instrumento para lograr un mejor resultado, tanto académico como en el aspecto de la sociabilidad. Hay conciencia de que las noticias, tanto de la prensa escrita como la televisión, muestran que la violencia en los establecimientos escolares es una realidad. La escuela es el lugar que acoge a niños, niñas jóvenes durante 10 meses del año, lo cual está haciendo un llamado imperioso a las conciencias de los adultos, lo cual está indicando lo poco o nada que se está entregando como agentes socializadores.

Los educandos traen a los establecimientos una carga enorme de emociones, a veces entregadas por sus padres, por el medio que habitan y donde se socializan; estas son por supuesto muchas veces negativas y estresantes, además los alumnos muchas veces se aburren en las clases monótonas donde no existe la creatividad, y donde el profesor se limita a pasar la clase anotando en el pizarrón, esto produce en ellos más violencia, pues al quedarse dormidos o al tener poco interés, empiezan a producir conductas que entorpecen el buen rendimiento.

Para efectuar cualquier actividad en los Colegios es necesario contar con la ayuda y la confianza de la dirección del establecimiento. Para la realización de este proyecto es adecuado que las ideas sean recibidas con la ayuda y la cooperación necesaria, además de realizar un trabajo en conjunto con el Encargado de la Biblioteca.

El objetivo general del proyecto es Acercar a los niños y jóvenes al libro y la lectura. Entre los objetivos específicos se destacan: (i) Lograr habilidades que enriquezcan a los estudiantes. (ii) Lograr una mayor cohesión con el grupo que se está educando. (iii) Crear espacios dentro del establecimiento que ayuden de alguna manera a la socialización y la unión del grupo. (iv) Incentivar el hábito de la lecto-escritura mediante el juego lúdico. (v) Realizar talleres literarios.

Considerando que la biblioteca, un lugar para compartir, cabe preguntarse: ¿Cómo lograr que la biblioteca sea un espacio ameno que encante a los pequeños y jóvenes? Para esto es necesario contar con un espacio amplio, con mesas y asientos confortables, con luz apropiada y con todo lo necesario para llevar a cabo el proyecto. ¿En qué momento lograr encantar a los niños y jóvenes? Se puede realizar en un momento u horario que no produzca trastornos en la 
educación, y además, en un momento en que ellos vayan libremente, sin presiones de ningún tipo. Entonces, los recreos son el espacio perfecto para lograr los objetivos antes expuestos y así evitar la violencia (bulling) y lograr el objetivo fundamental que es el acercamiento al libro y la lectura.

Para llevar a cabo esta actividad se necesitan los siguientes implementos: (i) Juegos de salón, como ajedrez, metrópolis, dados, ludo etc. (ii) Libros entretenidos que estén dispuestos de manera estratégica y colorida para atrapar a los lectores. (iii) Vitrinas donde estén exhibidos los libros que pueden solicitar al director de la biblioteca. (iv) Muñecos de trapo que relacionan el libro con los personajes. (v) Espacio para realizar cuenta cuentos, que las propias alumnas efectúan a los más pequeños, bajo la supervisión de la profesora de taller. (vi) Mesas y sillas para escribir, dibujar y pintar los cuentos y sus personajes. (vii) Lápices, hojas, todo tipo de papeles para confeccionar las portadas y tarjetas. (viii) Computador para bajar información y además juegos.

A continuación se describe la organización y ejecución del proyecto: Este fue ideado para que las propias alumnas y alumnos, tengan una organización y se sientan responsables de los recursos que tiene la biblioteca; por este motivo se escogieron siete niños y niñas a los que se les denominó ayudantes de biblioteca, portando una plaquita en sus delantales que los acreditan como tales. Cada cierto tiempo se realizaban reuniones, para que ellos aprendan a dialogar y expresar opiniones. A los tres meses de implantado el programa se pudo observar que las expectativas habían sobrepasado lo que se estimó en un principio. En el camino se fueron inventando estrategias diferentes, tales como: campeonatos de ajedrez, concursos de cuentos y poesías, curso de chino mandarín -dictado por el bibliotecario del colegio-, presentaciones de cuentos y teatro de títeres realizados por los mismos alumnos a los que se les incentivó para que día a día invitaran a diferentes cursos de los más pequeños para que participaran con ellos. Todo esto fue causando en los profesores ansias de compartir lo que sabían, y fueron integrándose al proyecto y agregándole cada uno motivaciones que hacían cada vez más prometedor el resultado. Al terminar el primer año de aplicación del proyecto se hizo una evaluación y se pudo comprobar, que la biblioteca se hacía pequeña, y que los niños que en un principio entraban con muy poca disciplina, se habían ido dando cuenta que todo era mejor con una organización. Se constató con una estadística que la manejaban los propios alumnos y el director de biblioteca, que se habían pedido más libros que años anteriores para leerlos en la casa; además, que otros que en un principio solo venían para jugar, ahora se habían convertido en lectores y narradores, puesto que todos tienen una idea creativa que requiere ser 
escuchada y dar el espacio necesario para ello. Los resultados de cada año fueron analizados, llegando a la conclusión a fines del año 2019 que la biblioteca se convirtió en un espacio de integración y amistad, y de fomento de la lectura y escritura, el puntaje en SIMCE $^{5}$ subió, especialmente en los cuartos básicos en un $10 \%{ }^{6}$; hubo que planificar actividades en la asignatura de lenguaje porque la cantidad de alumnos fue cada vez mayor pudiendo llegar a una conclusión: La necesidad de seguir ocupando la biblioteca como centro de conocimientos y amistad.

Esta experiencia se ha aplicado por 5 años y ha quedado demostrado que los estudiantes han encontrado en este espacio una forma de dar rienda a suelta a su creatividad. A su vez, se fue mejorando, tanto la lectura como el comportamiento de los escolares en los lugares donde deben compartir, logrando de esta manera la socialización, y una más sana y mejor convivencia, demostrando que la biblioteca puede convertirse en un espacio de integración y amistad.

FIGURA 2 - Alumnos representando una obra en la Biblioteca.

\footnotetext{
${ }^{5}$ Sistema de Medición de la Calidad de la Enseñanza. Es una prueba estandarizada, similar a PISA usada por los países de la OCDE -al cual pertenece Chile desde 2010- que se aplica en el país desde 1982, especialmente en lenguaje, matemáticas y ciencias naturales y sociales a los cuartos básicos, octavos básicos y segundos medios. ${ }^{6}$ Datos revisados en los resultados entregados por la Agencia de Calidad del Ministerio de Educación que efectúa la prueba y entrega los resultados, en el período 2015-2019.
} 


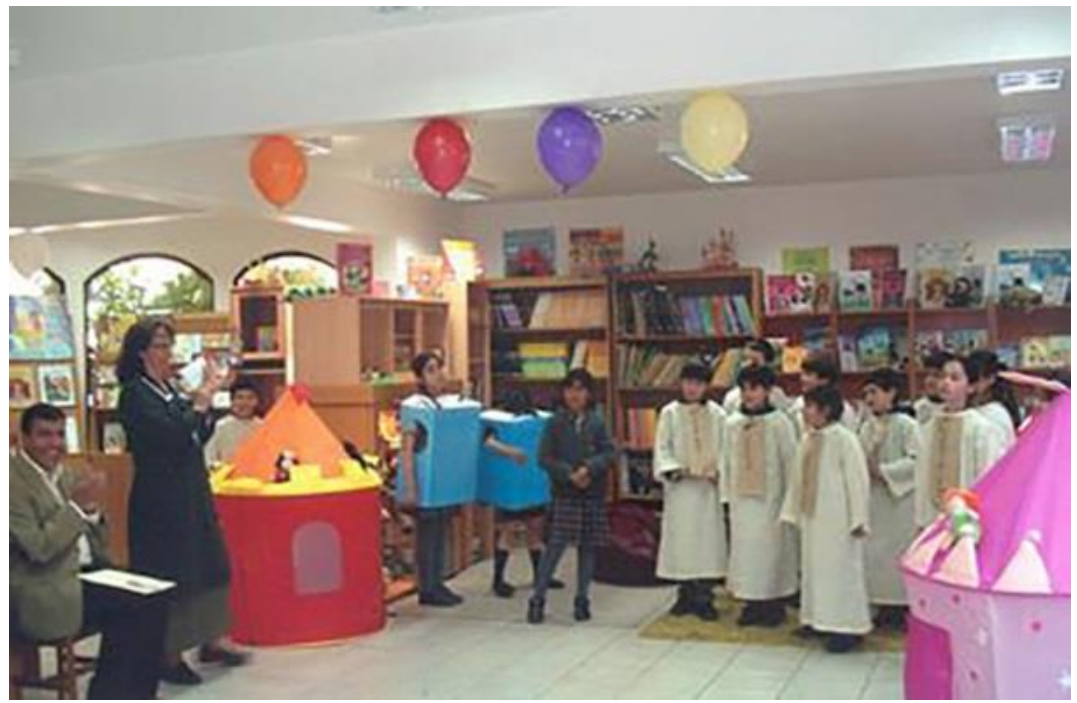

Fuente: Foto archivo personal autores.

FIGURA 3 - Reinaldo Lacámara, Presidente de la SECH, Estela Socías, Jaime Caiceo, Hna. Bernarda, Superiora Colegio Santa Isabel de Hungría en Biblioteca del Colegio.

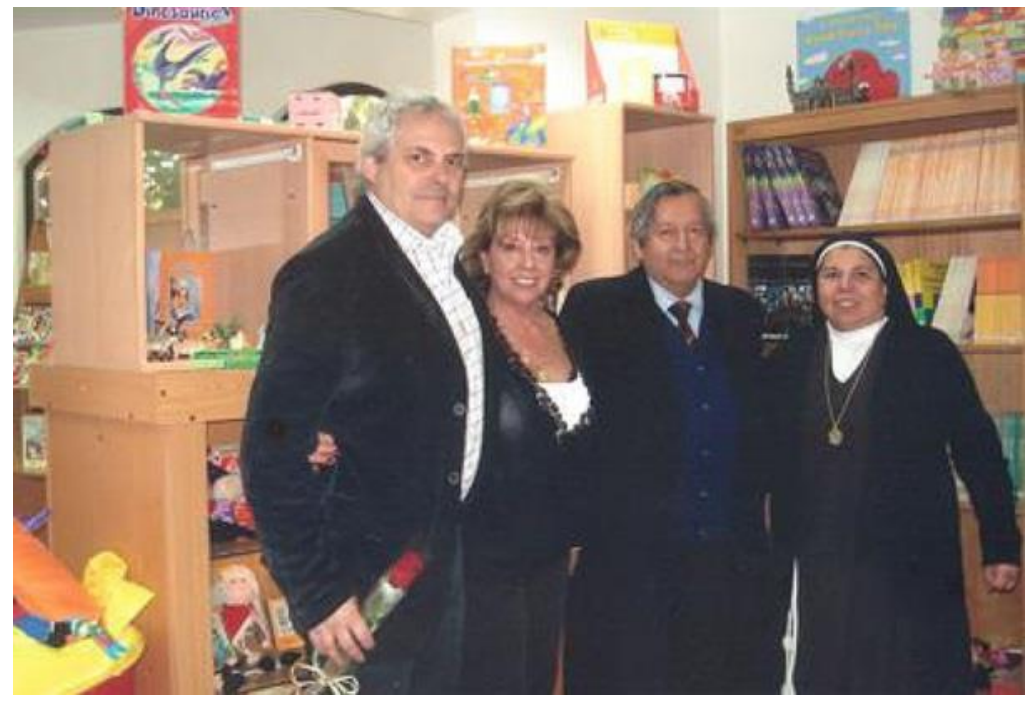

Fuente: Foto archivo personal autores.

Este proyecto se replicó en otros establecimientos educacionales, tanto públicos como particulares. La supervisión de la ejecución ha estado a cargo de los bibliotecarios respectivos. Al hacer una evaluación, el nivel de aprendizaje y el acercamiento a la lecto-escritura ha ido en aumento y, al mismo tiempo como toda actividad necesita cambios, se han ido haciendo mejoramientos en aquellas actividades que atraen más a los alumnos.

\section{PUBLICACIONES DE CUENTOS CON MUÑECOS Y LIBROS RELIGIOSOS}


Desde la ACHLI, su Presidenta, Estela Socías, escribió cuentos de muñecos de trapo que hablan, confeccionando los personajes relevantes de cada texto, de manera que los educandos pudieran de una forma lúdica compenetrar en la vida de estos, y al mismo tiempo realizar una labor sicopedagógica, ya que, al enfrentar el niño esta realidad, se involucra con la vida del muñeco, personaje principal de la historia y con su propia voz.

Se lograron buenos resultados, ya que los más tímidos comenzaron a contar los cuentos mostrando las láminas y haciendo hablar a su muñeco y aunque no sabían algunos leer por su edad, se les quedaban gravados en su mente los que habían escuchado por la experta y habían observado las láminas y los muñecos.

FIGURA 4: Muñecos de trapo de los distintos cuentos.

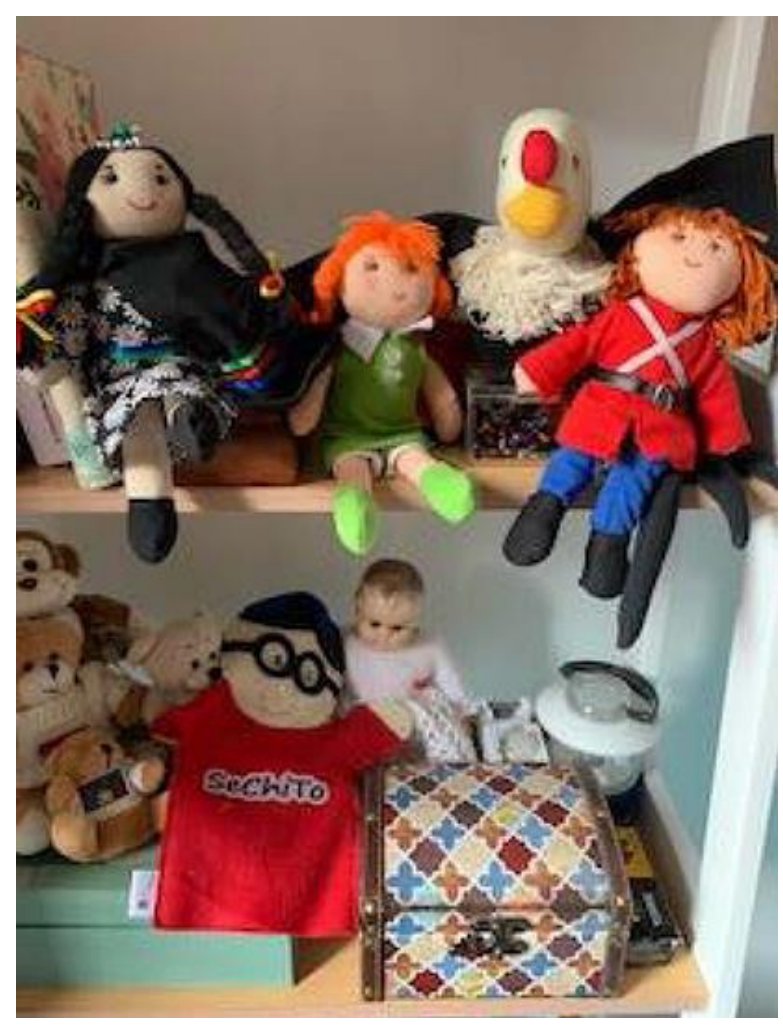

Fuente: Foto archivo personal autores.

De ahí nació la serie de Trapolandia, el país de los muñecos de trapo, donde se editaron cinco libros como Carmelita la muñeca de trapo, Las aventuras del club Hilario, El mago Anastasio, El duende Serafín, y Carmelita en el país de los corazones, este último para celebrar los 150 años de las Hijas de la Caridad y los Padres de la Misión en Chile. Esta era una forma concreta para incentivar a la lecto-escritura a los infantes de los primeros años de escolaridad. 
FIGURA 5 - Libros Colección Trapolandia.
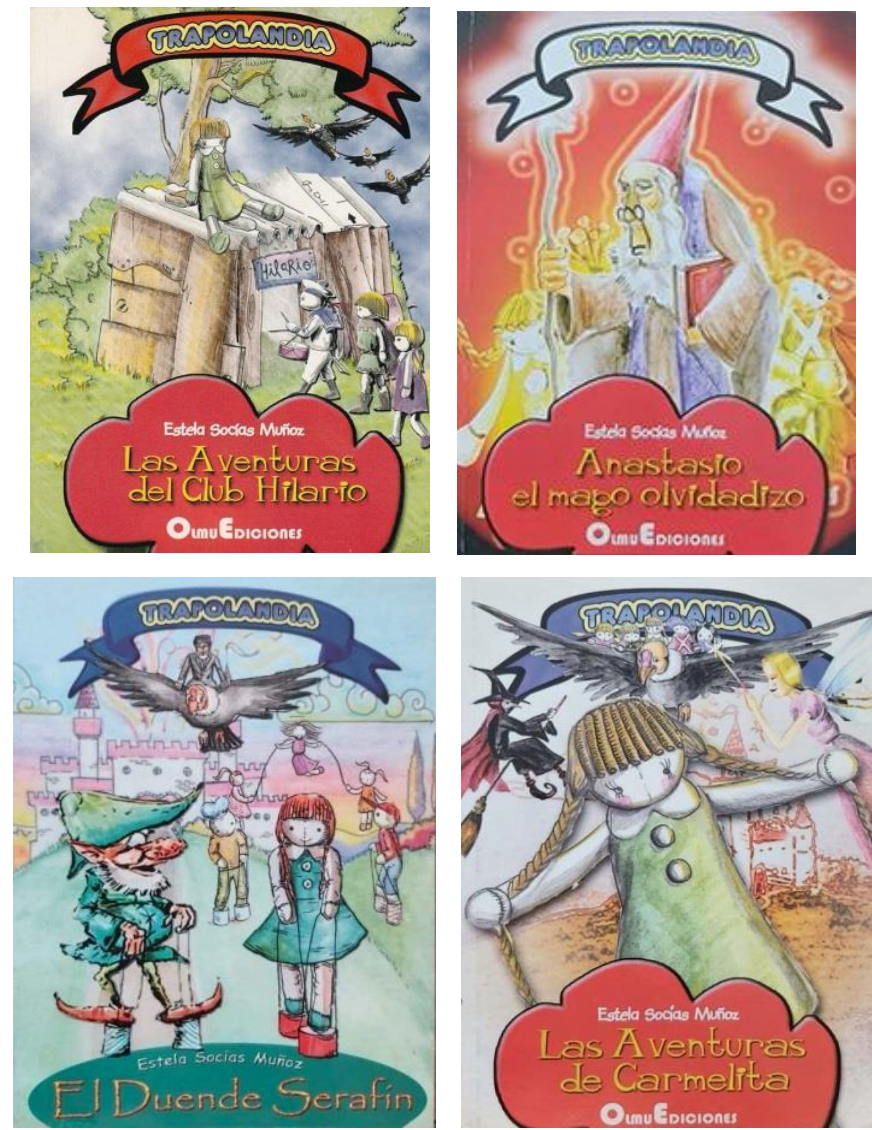

Fuente: Foto archivo personal autores.

En los dos colegios mencionados en el punto anterior, gracias a la Ley de Subvención Escolar Preferencial ${ }^{7}$-SEP- (2008), el Director de los mismos solicitó a Estela Socías que escribiera libros donde los valores universales mezclados, tanto en los libros religiosos -con la vida de santos fundadores de cada congregación que eran las sostenedoras ${ }^{8}$ de los establecimientos- como en otro tipo de cuentos con animalitos que hablan, pudiera realizar talleres y, al mismo tiempo, mostrar a los niños y niñas mediante estos relatos, aquellos principios tan importantes como lo es la de fomentar desde pequeños valores de solidaridad, honestidad, justicia, amor al prójimo y la lecto-escritura, mezclados con la fantasía y la

\footnotetext{
${ }^{7}$ Esta ley tiene por objetivo mejorar la calidad y equidad de la educación en los establecimientos educacionales que atienden alumnos cuyas condiciones socioeconómicas pueden afectar su rendimiento escolar; se les llama alumnos prioritarios o preferentes; el estado entrega recursos especiales para realizar actividades que mejoren los resultados educacionales de esos estudiantes.

${ }^{8}$ Se entienden por sostenedores a quienes son propietarios de un establecimiento educacional; los sostenedores reconocidos por el estado pueden optar a la gratuidad y el Ministerio de Educación entrega los recursos para su funcionamiento. Para optar a la Ley SEP hay que ser establecimiento educacional subvencionado por el estado.
} 
creatividad. Como una manera de introducir a los infantes en los valores de los Proyectos Educativos de los colegios se le entregaba a cada niña o niño un libro escrito en lenguaje infantil, muy didáctico e ilustrado con figuras que incentivaran a la lectura. En la fiesta aniversario de cada establecimiento educacional se entregaba un libro diferente a todos los estudiantes de los primeros niveles de escolaridad. Esta era una manera concreta de ayudar a las niñas y niños a ir armando una pequeña biblioteca en sus hogares.

FIGURA 6 - Textos sobre vida de Santos.
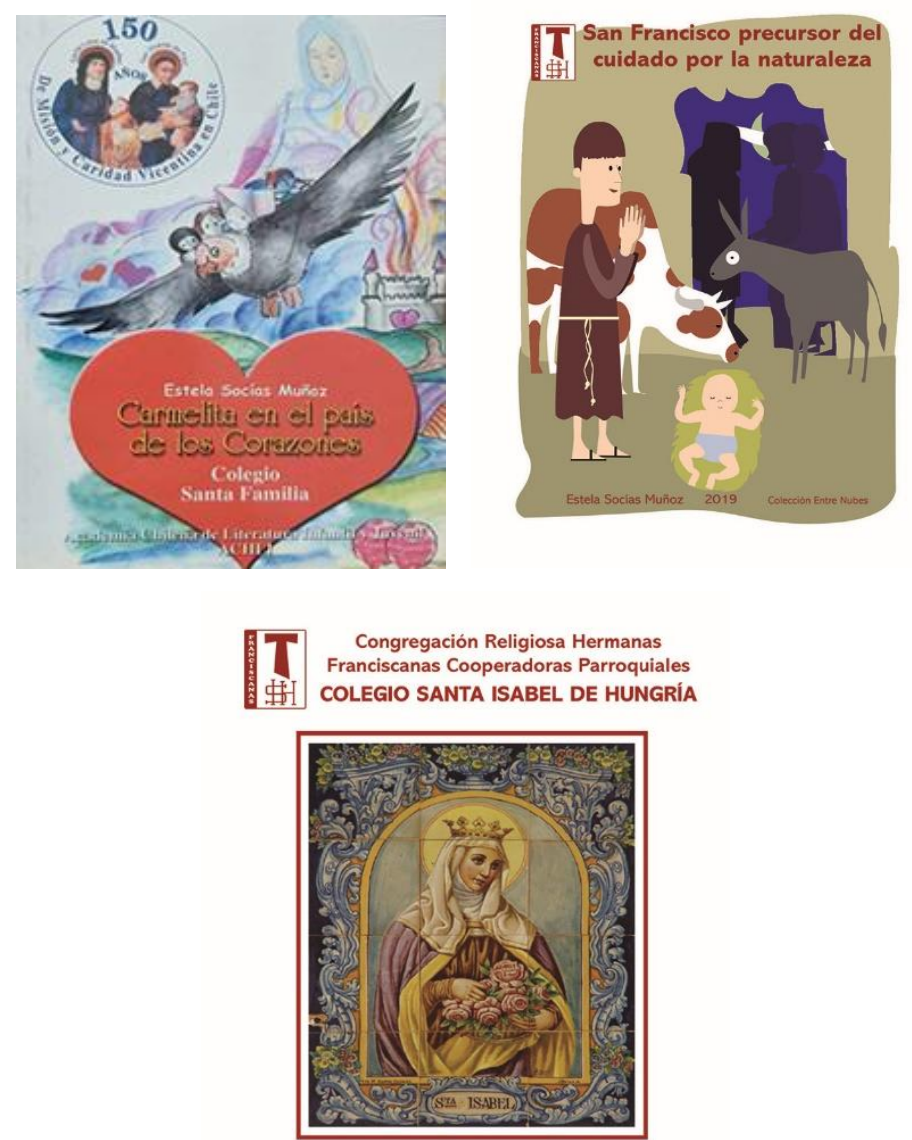

SANTA ISABEL DE HUNGRIA:

"Una Vida Consagrada a Cristo en la persona de los pobres" 2019 - Santiago - Chile

Fuente: Foto archivo personal autores.

Al mismo tiempo, se promovían concursos literarios, cuyo personaje promotor era SECHITO; cada año este muñeco formó parte del imaginario de los niños y jóvenes, quienes participaban en estos concursos, para luego ser premiados en la Feria Internacional del Libro y la lectura -que se efectúa anualmente en el centro de Santiago-, y realizar actividades como teatro infantil, vistiéndose como sus muñecos; todo esto se sigue incluso este año aunque la participación y la entrega de premios se hará online; este año el concurso se le denominó 
"Sechito mira por la ventana"; de esta forma los niños podrán expresar sus sentimientos que le han ocurrido al cambiar de un día para otro la visión del mundo, entre ellas la más importante la de compartir presencialmente, vía telemática, con sus compañeros en el colegio y en los recreos de aquellas cosas que iluminan su vida futura.

\section{CONCLUSIÓN}

Al finalizar este artículo teórico-práctico se puede concluir que se han concretado los tres objetivos planteados inicialmente, pues se ha realizado una investigación acuciosa acerca de la importancia y las funciones de la Literatura Infantil, se ha descrito el rol que el docente debe tener para promoverla y se han mostrado estrategias concretas de experiencia en Chile que favorecen el aprendizaje natural de la lectura, relacionadas con la literatura para niños. Se ha podido constatar la importancia que adquiere el compromiso de los directores de los establecimientos educacionales con el fomento a la lectura en los infantes. Al mismo tiempo, se ha confirmado que con creatividad, a través de los libros y personajes que se encuentran en ellos es posible entregar una educación con valores que tanta falta hace en estos momentos en el mundo que rodea a nuestros niños; en el individualismo global existente es necesario inculcar la solidaridad para que se avance hacia una sociedad más justa e inclusiva. La escuela hoy en día no solo debe formar buenos profesionales sino que buenas personas y buenos ciudadanos. En todo caso, habría que realizar una investigación empírica para poder constatar que efectivamente a través de lecturas seleccionadas es posible concretar la formación en valores; lo afirmado en líneas anteriores se plantea a modo de hipótesis a demostrar, de tal manera que la conclusión de lo descrito en este artículo sirva de base para continuar estudiando la relación lectura-axiología en la educación de las escuelas.

\section{BIBLIOGRAFÍA}

\section{ALLIENDE, Felipe; CONDEMARÍN, Mabel. De la asignatura de castellano al área del lenguaje. Santiago de Chile: Dolmen Ediciones, 1997. 244 p.}

BIBLIOTECA NACIONAL DE CHILE. Decreto $\mathrm{n}^{\circ}$ 58: Fija texto refundido, coordinado y sistematizado de la Ley $N^{\circ} 19.418$, sobre Juntas de Vecinos y demás Organizaciones Comunitarias. Diario Oficial. Santiago de Chile, promulgado el 20 de marzo de 1997. 
BIBLIOTECA DEL CONGRESO NACIONAL. Ley ${ }^{\circ} 20.248$ que establece la Ley de Subvención Escolar Preferencial. Diario Oficial. Santiago de Chile, promulgado el $1^{\circ}$ de febrero de 2008.

BUBER, Martín. Yo y Tú. Barcelona: Editorial Herder, 2017. 164 p.

CAICEO, Jaime. Relaciones de la Literatura Infantil con la Filosofía y la Gestión Educacional. Em: CAICEO, Jaime (Editor). Leer desde la Cuna: un gran desafío. Santiago de Chile: Ediciones Consejo Nacional de la Cultura y las Artes en coedición con la Academia de Literatura Infantil-Juvenil -ACHLI- y Universidad Mayor, 2006. p. 45-50.

CAICEO, Jaime. Pensamiento pedagógico en Chile en el siglo XX y sus proyecciones. Cadernos de História da Educação, v. 11, n. 1, p. 207-226, 2012.

CAICEO, Jaime. La Pedagogía de Dewey en Chile: su presencia, a través de sus discípulos, durante el siglo XX. Santiago de Chile: Ediciones Universidad de Santiago de Chile, 2016. $174 \mathrm{p}$.

CAICEO, Jaime. El Porqué del Desarrollo Insuficiente de la Filosofía de las Ciencias Sociales. El Futuro del Pasado, Salamanca, nº 9, p. 393-418, 2018.

CAICEO, Jaime. Memorias de la academia chilena de literatura infantil juvenil. Santiago de Chile: Informe a Ilustre Municipalidad de Providencia, entidad que otorga la personalidad jurídica, 2019. 88 p.

GADAMER, Hans-Georg (1993). Verdad y Método. Fundamentos de una Hermenéutica Filosófica. Tomo I. 5. ed. Salamanca: Ediciones Sígueme, 1993. 205 p.

HURTADO, Jacqueline. Metodología de la Investigación. Guía para la Comprensión Holística de la Ciencia. 4. ed. Bogotá-Caracas: Ediciones Quirón, 2010. 1.330 p.

HUSSERL, Edmund. Ideas Relativas a una Fenomenología Pura y una Filosofía Fenomenológica. México: Fondo de Cultura Económica, 1962. 522 p.

LUKENS, Rebeca. A critical handbook of children's literature. 6th edition New York: Longman, 1999. 378 p.

MEMORIA CHILENA. Marcela Paz (1902-1985). In: http://www.memoriachilena.gob.cl/602/w3-article-3595.html. Consultado el: 19 ago. 2020.

MORENO, Antonio (1998). Literatura Infantil: Introducción en su problemática, su historia y su didáctica. 2 ed. Cádiz: Servicios de Publicaciones de la Universidad.

QUINTEROS, D. Tipos de escrito. Madrid: Arco Libros, 1992. 168 p.

SMITH, Frank. Reading Without Nonsense. New York: Teachers College Press, 1979. 166 p.

SMITH, Frank. Writing and the Writer. New York: Holt Rinehart \& Winston, 1982. 257 p. 
SOCÍAS, Estela. ¿Qué son los libros? En: CAICEO, Jaime (Editor). Leer desde la Cuna: un gran desafío. Santiago de Chile: Ediciones Consejo Nacional de la Cultura y las Artes en coedición con la Academia de Literatura Infantil-Juvenil -ACHLI- y Universidad Mayor, 2006. p. $9-18$.

VANNINI, M. Literatura infantil. Caracas: Universidad Nacional Abierta, 1995. 185 p.

Recebido em: 29 de agosto de 2020 Aceito em: 03 de setembro de 2020 